\title{
Application of Taguchi and regression analysis on surface roughness in machining hardened AISI D2 steel
}

\author{
Ashok Kumar Sahoo*
}

School of Mechanical Engineering, KIIT University, Bhubaneswar-24, Odisha, India

\section{H R O N I C L E}

\begin{tabular}{l}
\hline Article history: \\
Received July 22013 \\
Received in revised format \\
September 72013 \\
Accepted October 232013 \\
Available online \\
November 152013 \\
\hline Keywords: \\
Coated carbide \\
Taguchi \\
Surface roughness \\
ANOVA \\
Regression
\end{tabular}

A B S T R A C T

\begin{abstract}
The objective of the study is to assess the performance of multilayer coated carbide insert in the machining of hardened AISI D2 steel (53 HRC) using Taguchi design of experiment. The experiment was designed based on Taguchi L27 orthogonal array to predict surface roughness. The $\mathrm{S} / \mathrm{N}$ ratio and optimum parametric condition are analysed. The analysis of variance has also been carried out to predict the significant factors affecting surface roughness. Based on Taguchi $\mathrm{S} / \mathrm{N}$ ratio and ANOVA, feed is the most influencing parameter for surface roughness followed by cutting speed whereas depth of cut has least significant from the experiments. In regression model, the value of $\mathrm{R}^{2}$ being 0.98 indicates that $98 \%$ of the total variations are explained by the model. It indicates that the developed model can be effectively used to predict the surface roughness on the machining of D2 steel with $95 \%$ confidence intervals.
\end{abstract}

\section{Introduction}

Machining is a finishing process by which jobs are produced to the desired dimensions and surface finish by removing the unwanted material from the preformed blank in the form of chips with the help of cutting tools. Therefore, in order to obtain machining process effectively, efficiently and economically, proper selection of cutting tool materials is important. Recently, with the development of coated cutting tool materials, it is possible now to machine at higher cutting speed thus improves productivity and applies to moderate range of hard turning. Traditionally, grinding is accepted as the preferred method of machining materials with hardness greater than $50 \mathrm{HRC}$. The advent of super hard tool materials, such as ceramic and CBN tools, has made it possible to replace slow traditional grinding practice for hardened steels to produce desired quality. Many researchers have tried by utilizing CBN and ceramic tool in hard machining. But the potential of using multilayer grade of coated carbide in hard machining is still limited.

* Corresponding author.

E-mail: aklala72@gmail.com (A. K. Sahoo)

(C) 2014 Growing Science Ltd. All rights reserved. doi: $10.5267 /$ j.ijiec.2013.11.001 
Recently, Davim and Figueira (2007) investigated the machinability of AISI D2 cold work tool steel using ceramic inserts that produces surface finish as good as by cylindrical grinding. Quiza et al. (2008) investigated on predicting tool wear in hard machining D2 AISI steel using neural networks. The neural network model indicated better capability to make accurate predictions of tool wear under the conditions studied. Ozel et al. (2007) investigated the surface finish and tool flank wear in finish hard turning of AISI D2 steels (60 HRC) using ceramic wiper (multi-radii) design inserts. Noordin et al. (2001) used TiAlN coated carbide tool to finish machine of hardened steel. Performing hard turning dry at various cutting conditions, that is, cutting speed and feed rate, revealed that satisfactory tool life values and surface finish values that meet the strict range of finish machining were obtained when finish machining hardened steel of 47-48 HRC hardness.

Thamizhmanii et al. (2008) analyzed the surface roughness produced by turning process on hard martensitic stainless steel by Cubic Boron Nitride cutting tool. Vikram Kumar et al. (2008) carried out on the comparative performance of TiCN and TiAlN coated tools in machining of AISI 4340 hardened steel under dry, wet and minimum fluid application conditions. The performance of the TiAlN tool was observed to be better; this is particularly true with reference to wear resistance of the tools and better surface finish on the components. Paiva et al. (2007) utilized alternative hybrid approach combining response surface methodology (RSM) and principal component analysis (PCA) to optimize multiple correlated responses in turning of AISI 52100 steel with mixed ceramic tool. Sahin (2009) described the comparison of tool life between ceramics and cubic boron nitride $(\mathrm{CBN})$ cutting tools when machining hardened bearing steels using the Taguchi method. First order linear, second order and exponential models were carried out to find out the correlation between cutting time and independent variables. The results indicated that the cutting speed was found to be a dominant factor on the tool life, followed by the tool hardness, lastly the feed. The CBN cutting tool showed the best performance than that of ceramic based cutting tool. Gaitonde et al. (2009) studied the machinability characteristics of hardened D2 steel in turning with ceramic cutting tool to justify the benefits over grinding process.

Ozel and Karpat (2005) utilized neural network modeling to predict surface roughness and tool flank wear over the machining time for variety of cutting conditions in finish hard turning of AISI H13 steel bar. Overall, CBN inserts with honed edge geometry performed better both in terms of surface roughness and tool wear development. Sahoo and Sahoo (2012) studied on flank wear, surface roughness, chip morphology and cutting forces in finish hard turning of AISI 4340 steel using uncoated and multilayer TiN and $\mathrm{ZrCN}$ coated carbide inserts at higher cutting speed range. The process has also been justified economically for its effective application in hard turning. Singh and Rao (2007) developed mathematical model for surface roughness using RSM. Feed was the dominant factor determining the surface finish followed by nose radius and cutting velocity in finish hard turning of the bearing steel AISI 52100 using mixed ceramic inserts. Though, the effect of the effective rake angle on the surface finish was less, the interaction effects of nose radius and effective rake angle were considerably significant. Sahoo and Sahoo (2011) presented the experimental study, development of mathematical model and parametric optimization for surface roughness in turning D2 steel using TiN coated carbide insert using Taguchi parameter design and response surface methodology. It is concluded that the developed RSM model can be effectively utilized to predict the surface roughness in turning D2 steel. Basak et al. (2007) carried out the optimization of a finish hard turning process for the machining of D2 steel with ceramic tools using neural network models to predict the surface roughness and tool wear as functions of cutting speed, feed, and machining time and found suitable to choose the appropriate process parameters. Sahoo and Sahoo (2013) studied the turning of hardened AISI 4340 steel $(47 \pm 1 \mathrm{HRC})$ using coated carbide inserts $\left(\mathrm{TiN} / \mathrm{TiCN} / \mathrm{Al}_{2} \mathrm{O}_{3} / \mathrm{ZrCN}\right)$ under dry environment. This shows the potential and effectiveness of multilayer coated carbide insert used in hard turning applications. Sahoo et al. (2013) development of flank wear model in turning hardened EN 24 steel with PVD TiN coated mixed ceramic insert under dry environment. The paper also investigated the effect of process parameter on flank wear $(\mathrm{VBc})$. Abrasion and diffusion has been found to be the dominant wear mechanism in machining hardened steel from SEM micrographs at highest parametric range. 
Machining time has been found to be the most significant parameter on flank wear followed by cutting speed and feed as observed from main effect plot and ANOVA study. Aggarwala et al. (2008) investigated the power consumption in hard turning of AISI P-20 tool steel (32-36 HRC) using TiN coated carbide insert with Taguchi's and RSM technique. Cryogenic environment was the most significant factor in minimizing power consumption followed by cutting speed and depth of cut. The effects of feed rate and nose radius were found to be insignificant. RSM technique was found to be better than Taguchi's method.

Sahoo and Mohanty (2013) utilized the application of Taguchi's parameter design to optimize the parameters for individual responses. For multi-response optimization, Taguchi's quality loss function approach is proposed. The effectiveness of the proposed methodology is illustrated through an experimental investigation in turning mild steel workpiece using high speed steel tool. Sahoo et al. (2013) presented the development of $\mathrm{Al} / \mathrm{SiCp}$ (10\% weight) metal matrix composite through a conventional casting process and studied its machinability characteristics in turning using multilayer TiN coated carbide insert under dry environment based on Taguchi's $\mathrm{L}_{9}$ orthogonal array. The regression models are highly significant because of higher $\mathrm{R}^{2}$ value. The experimental and predicted values are very close to each other. Sahoo and Sahoo (2013) studied the machinability aspects such as flank wear, chip morphology, surface roughness in finish hard turning of AISI 4340 steel (HRC $47 \pm 1$ ) using multilayer coated carbide $\left(\mathrm{TiN} / \mathrm{TiCN} / \mathrm{Al}_{2} \mathrm{O}_{3} / \mathrm{TiN}\right)$ insert under dry environment. Parametric influences on turning forces are also analyzed. From the machinability study, abrasion and chipping are found to be the dominant wear mechanism in hard turning. Multilayer TiN coated carbide inserts produced better surface quality and within recommendable range of 1.61 microns i.e. comparable with cylindrical grinding. Sahoo and Sahoo (2013) presented the mathematical modeling and parametric optimization on flank wear and surface roughness based on response surface methodology and greybased Taguchi method in finish hard turning of AISI 4340 steel (HRC $47 \pm 1$ ) using multilayer coated carbide (TiN/TiCN/Al $\left.\mathrm{O}_{2} \mathrm{O}_{3} / \mathrm{TiN}\right)$ insert under dry environment. The economical feasibility of utilizing multilayer TiN coated carbide insert has been described. Model adequacy has been checked using correlation coefficients.

The present paper performs some experiment on hard turning of AISI D2 steel (53 HRC) using multilayer coated carbide insert in wet cutting environment and optimize the process parameters using Taguchi design of experiment. The regression model has also been developed and checked for its adequacy.

\section{Experimental details}

The experiments were planned using Taguchi design of experiment (DOE), which helps in reducing the number of experiments. The experiments were conducted according to $\mathrm{L}_{27}$ orthogonal array (Ross). The independently controllable cutting parameters were (1) cutting speed, (2) feed rate, and (3) depth of cut. Machining experiments were carried out on a high rigidity AMS India CNC lathe of maximum spindle speed of $3500 \mathrm{rpm}, 16 \mathrm{KW}$ spindle power with Sinumeric controller under wet cutting conditions using servo cut-s as cutting fluid. The cutting performance tests were performed on a high carbon high chromium cold work tool steel AISI D2 bars of diameter $40 \mathrm{~mm}$ with the following chemical composition: $1.55 \% \mathrm{C}, 0.4 \% \mathrm{Si}, 0.4 \% \mathrm{Mn}, 11.80 \% \mathrm{Cr}, 0.7 \% \mathrm{Mo}, 0.5 \% \mathrm{~V}, 0.6 \% \mathrm{~W}, 0.03 \% \mathrm{~S}$ and $0.03 \% \mathrm{P}$. The bar was heat treated and found to be $53 \mathrm{HRC}$. Uncoated carbide tool was used to remove a layer of rust and scales from the surface of work piece prior to machining in a way so as to make the work piece diameter: length $=1: 4$. Commercially available multilayer coated $\left(\mathrm{TiCN} / \mathrm{Al}_{2} \mathrm{O}_{3} / \mathrm{TiN}\right)$ tungsten carbide insert (golden) was used for experimentation (Fig.1). The insert has the geometry designated by ISO as CNMG 120408 GS with $0.8 \mathrm{~mm}$ nose radius. The insert was rigidly mounted on a right hand style tool holder designated by ISO as PCLNR2525M12. The machining set up has been shown in Fig. 2. The arithmetic average surface roughness $(\mathrm{Ra})$ of the turned surface was measured using a surface roughness measuring tester (Taylor Hobson, surtronic 25) and of sampling length $0.8 \mathrm{~mm}$, evaluation length of $4 \mathrm{~mm}$ and of least count of $0.01 \mu \mathrm{m}$ (Fig. 3). Taguchi method (Ross, 2005) suggests the 
equation for calculating the $\mathrm{S} / \mathrm{N}$ ratio for smaller-the-better characteristics (in $\mathrm{dB}$ ) is $\mathrm{S} / \mathrm{N}_{\mathrm{LB}}=-10 \log _{10}$ $\left(1 / \mathrm{r} \Sigma \mathrm{R}_{\mathrm{i}}{ }^{2}\right)$ where $\mathrm{R}_{\mathrm{i}}$ is the value of surface roughness for the ith test in that trial. The machining parameters and their levels are represented in Table 1.

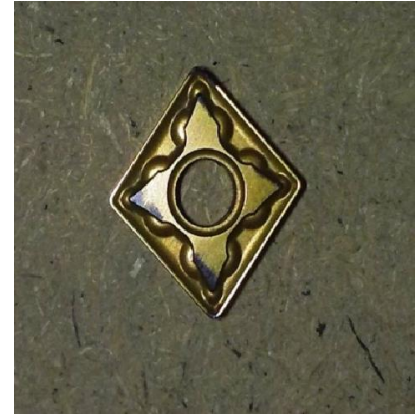

Fig.1. Cutting insert

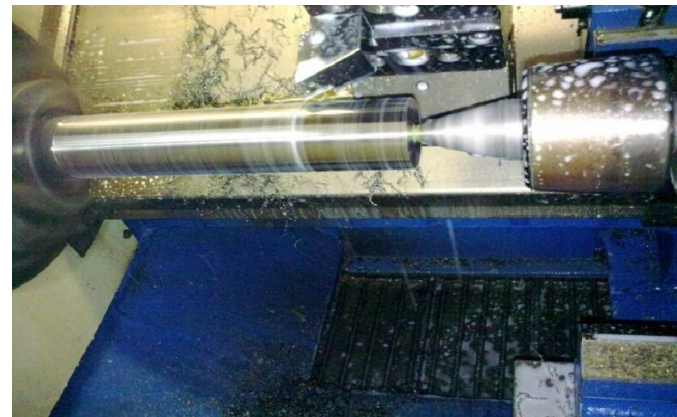

Fig. 2. Experimentation

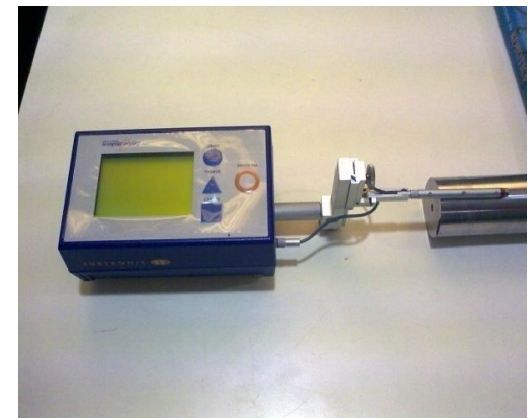

Fig. 3. Surface roughness tester (Taylor Hobson, Surtronic 25)

Table 1

Machining parameters and their levels

\begin{tabular}{lccc}
\hline Parameters & \multicolumn{2}{c}{ Levels } \\
\cline { 2 - 4 } & Level-1 & Level-2 & Level-3 \\
\hline v (Cutting speed, $\mathrm{m} / \mathrm{min})$ & 80 & 150 & 220 \\
$\mathrm{f}($ Feed, $\mathrm{mm} / \mathrm{rev})$ & 0.05 & 0.1 & 0.15 \\
$\mathrm{t}$ (Depth of cut, $\mathrm{mm})$ & 0.1 & 0.2 & 0.3 \\
\hline
\end{tabular}

\section{Results and discussions}

The results of the hard turning tests are summarized below (Table 2) in terms of surface roughness obtained in the hardened D2 steel work piece material (53 HRC) in wet cutting environment.

Table 2

Experimental results with $\mathrm{S} / \mathrm{N}$ ratios

\begin{tabular}{|c|c|c|c|c|c|}
\hline Run No & $\mathrm{V}$ & $\mathrm{f}$ & $\mathrm{t}$ & Ra (Microns) & $\mathrm{S} / \mathrm{N}$ ratios \\
\hline 1 & 80 & 0.05 & 0.1 & 0.55 & 5.192 \\
\hline 2 & 80 & 0.05 & 0.2 & 0.58 & 4.731 \\
\hline 3 & 80 & 0.05 & 0.3 & 0.62 & 4.152 \\
\hline 4 & 80 & 0.1 & 0.1 & 0.81 & 1.83 \\
\hline 5 & 80 & 0.1 & 0.2 & 0.85 & 1.411 \\
\hline 6 & 80 & 0.1 & 0.3 & 0.88 & 1.11 \\
\hline 7 & 80 & 0.15 & 0.1 & 1.17 & -1.363 \\
\hline 8 & 80 & 0.15 & 0.2 & 1.22 & -1.727 \\
\hline 9 & 80 & 0.15 & 0.3 & 1.29 & -2.211 \\
\hline 10 & 150 & 0.05 & 0.1 & 0.44 & 7.13 \\
\hline 11 & 150 & 0.05 & 0.2 & 0.48 & 6.375 \\
\hline 12 & 150 & 0.05 & 0.3 & 0.51 & 5.848 \\
\hline 13 & 150 & 0.1 & 0.1 & 0.72 & 2.853 \\
\hline 14 & 150 & 0.1 & 0.2 & 0.76 & 2.383 \\
\hline 15 & 150 & 0.1 & 0.3 & 0.8 & 1.938 \\
\hline 16 & 150 & 0.15 & 0.1 & 1.1 & -0.827 \\
\hline 17 & 150 & 0.15 & 0.2 & 1.15 & -1.213 \\
\hline 18 & 150 & 0.15 & 0.3 & 1.21 & -1.655 \\
\hline 19 & 220 & 0.05 & 0.1 & 0.31 & 10.172 \\
\hline 20 & 220 & 0.05 & 0.2 & 0.38 & 8.404 \\
\hline 21 & 220 & 0.05 & 0.3 & 0.42 & 7.535 \\
\hline 22 & 220 & 0.1 & 0.1 & 0.6 & 4.436 \\
\hline 23 & 220 & 0.1 & 0.2 & 0.64 & 3.876 \\
\hline 24 & 220 & 0.1 & 0.3 & 0.68 & 3.349 \\
\hline 25 & 220 & 0.15 & 0.1 & 0.97 & 0.264 \\
\hline 26 & 220 & 0.15 & 0.2 & 1.05 & -0.423 \\
\hline 27 & 220 & 0.15 & 0.3 & 1.11 & -0.906 \\
\hline
\end{tabular}




\subsection{Effect of process parameters on surface roughness}

The experimental results show that the average surface roughness is low at higher cutting speed and comparatively high at low cutting speed (Fig. 4). Surface roughness are low at low feed i.e. $0.05 \mathrm{~mm} / \mathrm{rev}$ as compared to the other levels of feed i.e. $0.1 \mathrm{~mm} / \mathrm{rev}$ and $0.15 \mathrm{~mm} / \mathrm{rev}$ (Fig. 5). The experimental results show that average surface roughness is higher at higher depth of cut and lower at lower depth of cut (Fig. 6). The higher feed rate led cutting tool to traverse the work piece too rapidly resulting in deteriorated surface quality. The increase in feed also increases the chatter, and it produces incomplete machining of work piece, which led to higher surface roughness. The results prove that the roughness of the machined surface is highly influenced by feed. At higher cutting speeds, BUE formation disappears and chip-tool contact length decreases resulting in the improvement of surface finish of the work piece. Also at higher cutting speeds, cutting zone temperature increases and thus in turn, softens and decreases strength of BUE. Depth of cut does not impact the surface roughness in the studied range, which could be used to improve productivity if it would not worsen the surface microstructure of the material and the dimensional and geometric accuracy. In case of the machined surface roughness, the TiN coated carbide tool produced lower surface roughness i.e. less than 8 microns in most cases. This was believed to be due to high hardness, wear resistance, low coefficient of friction and high diffusion barrier properties of the TiN coated material. Thus the capability of the TiN coated tool, which retains hardness at high temperature and transfers the heat more effectively, results in the improvement of tool. Therefore the TiN coated cutting insert gives the better surface roughness and performs better. This trend agrees well with the experimental observations.

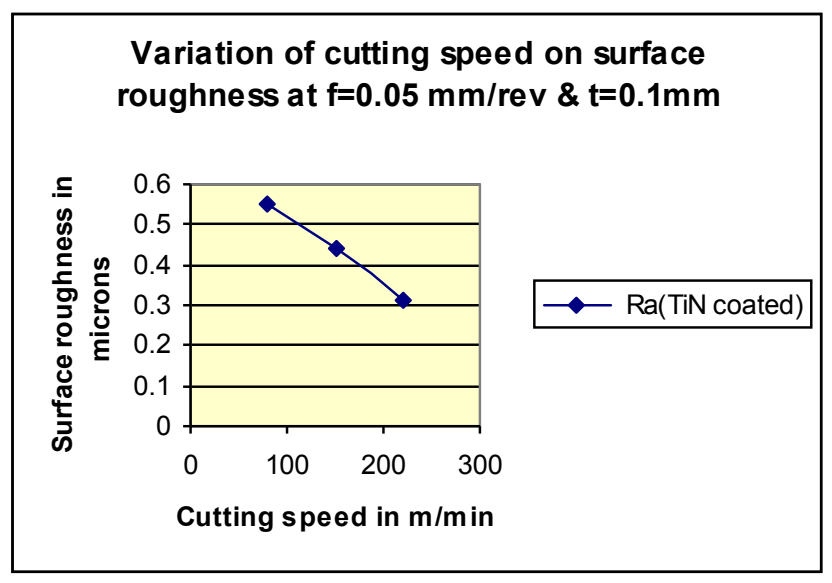

Fig. 4. Cutting speed vs. surface roughness

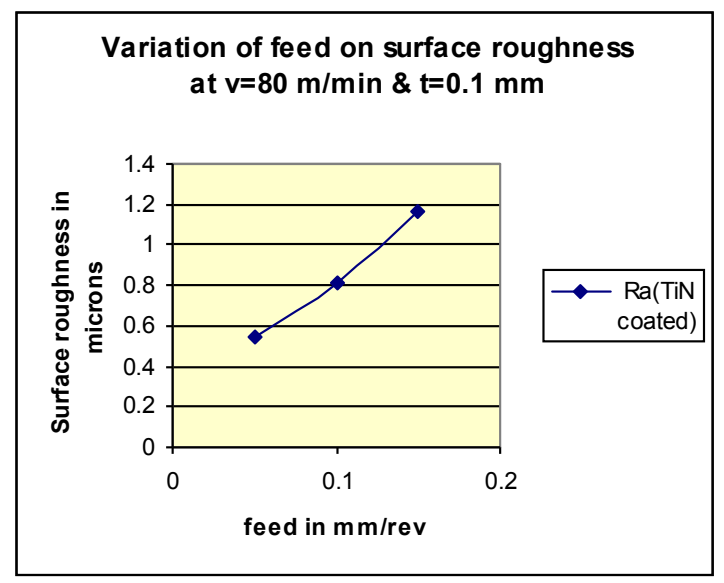

Fig. 5. Feed vs. surface roughness

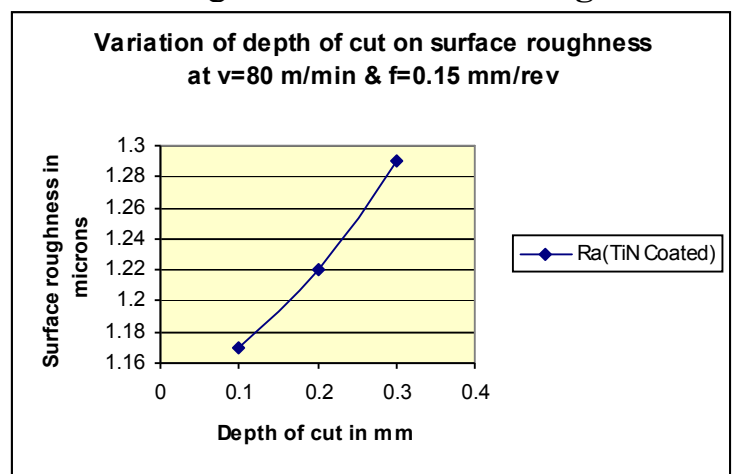

Fig. 6. Depth of cut vs. surface roughness

\subsection{Determination of optimal parameters}

The objective of using $\mathrm{S} / \mathrm{N}$ ratio is a measure of performance to develop products and processes insensitive to noise factors. The $\mathrm{S} / \mathrm{N}$ ratio indicates the degree of the predictable performance of a 
product or process in the presence of noise factors. Process parameters settings with the highest $\mathrm{S} / \mathrm{N}$ ratio always yield the optimum quality with minimum variance. The mean $\mathrm{S} / \mathrm{N}$ ratio for each level of the cutting parameters were summarized and called the mean $\mathrm{S} / \mathrm{N}$ response table for surface roughness shown in Table 3. Fig 7 shows the mean $\mathrm{S} / \mathrm{N}$ ratio graph for surface roughness. The $\mathrm{S} / \mathrm{N}$ ratio corresponds to the smaller variance of the output characteristics around the desired value. Therefore, based on the $\mathrm{S} / \mathrm{N}$ analysis, the optimal cutting parameters for surface roughness are the cutting speed at level-3, the feed at level-1, and the depth of cut at level-1 (v3-f1-t1).

\section{Table 3}

Response Table for surface roughness

\begin{tabular}{cccc}
\hline Level & $\mathrm{v}$ & $\mathrm{f}$ & $\mathrm{t}$ \\
\hline 1 & 1.458 & 6.616 & 3.299 \\
2 & 2.537 & 2.577 & 2.646 \\
3 & 4.079 & -1.118 & 2.129 \\
Max-Min & 2.62 & 7.734 & 1.17 \\
Rank & 2 & 1 & 3 \\
\hline
\end{tabular}

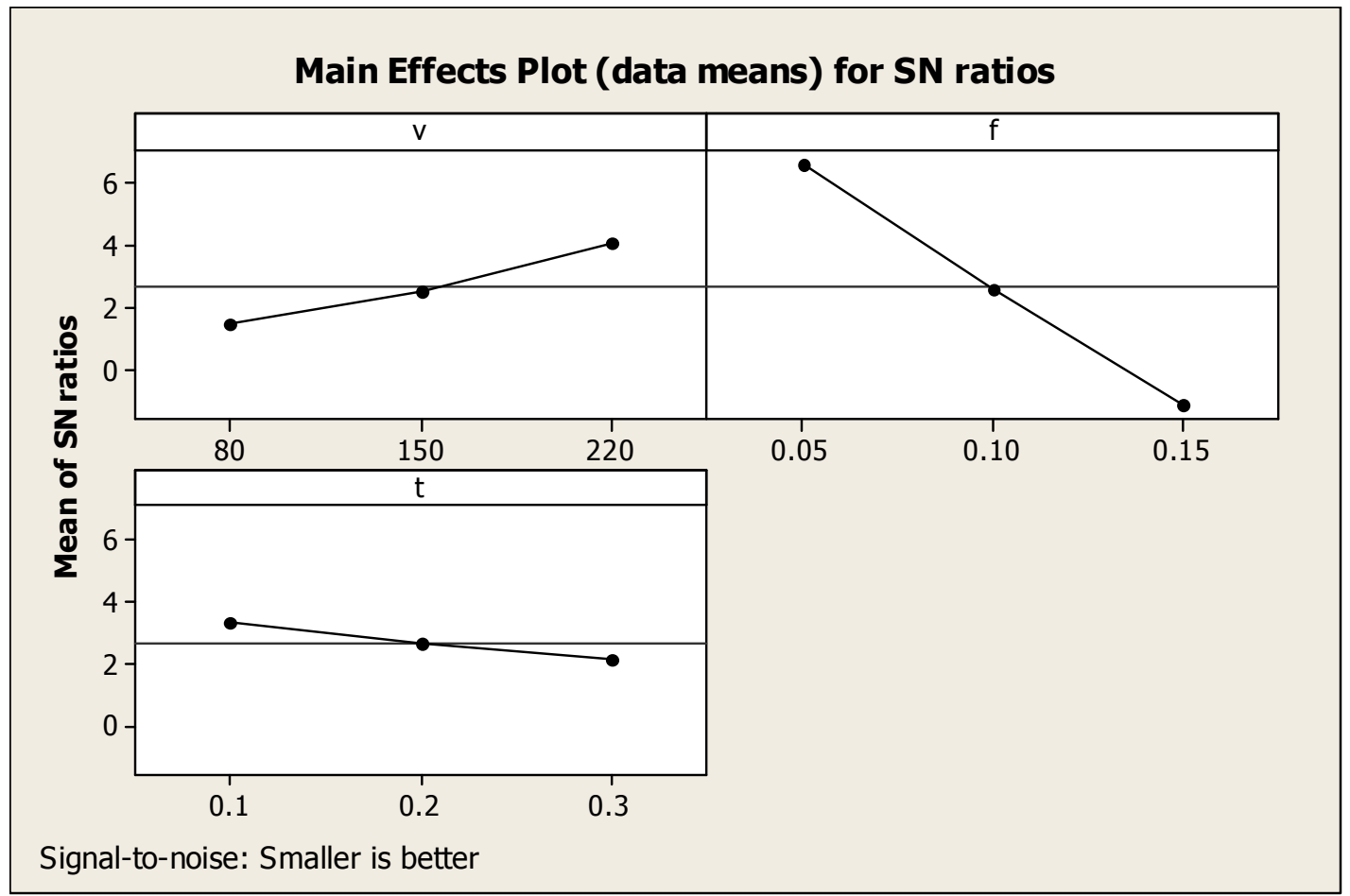

Fig. 7. Mean $\mathrm{S} / \mathrm{N}$ ratios for surface roughness

\subsection{Analysis of variance}

The purpose of the ANOVA is to investigate which of the process parameters significantly affect the performance characteristics. This analysis provides the relative contribution of machining parameters in controlling the response of machining performance criteria i.e. surface roughness during D2 turning. This is accomplished by separating the total variability of the $\mathrm{S} / \mathrm{N}$ ratios, which is measured by the sum of the squared deviations from the total mean of the $\mathrm{S} / \mathrm{N}$ ratio, into contributions by each of the process parameters and the error. Table 4 shows the results of analysis of variance for the $\mathrm{S} / \mathrm{N}$ ratio of the surface roughness. From ANOVA Table 4, it can be concluded that federate is the most significant variable affecting surface roughness for tool materials and its percentage of contribution is 85.74 . This inference agrees well with the experimental results. Next the cutting speed is also a significant variable as its contribution is $9.76 \%$ and $\mathrm{F}$ value is greater than table value. The depth of cut is a least 
significant variable as its percentage of contribution is only $1.87 \%$ and plays a minor role on machining process for surface roughness.

Table 4

ANOVA for $\mathrm{S} / \mathrm{N}$ ratio of the surface roughness

\begin{tabular}{ccccccc}
\hline SV & SS & DF & MS & F-Value & F (95 \%) & P (\%) \\
\hline v & 31.22 & 2 & 15.61 & 49.7 & 3.37 & 9.76 \\
f & 269.3 & 2 & 134.6 & 429 & 3.37 & 85.74 \\
t & 6.514 & 2 & 3.257 & 10.4 & 3.37 & 1.87 \\
Error & 6.295 & 20 & 0.314 & & & 2.63 \\
\hline Total & 313.3 & 26 & & & & 100 \\
\hline
\end{tabular}

\subsection{Regression model}

Finally, considering the most significant parameters, i.e. cutting speed, feed and depth of cut with notation of $\mathrm{v}, \mathrm{f}$ and $\mathrm{t}$ respectively, and with the help of test results for surface roughness of TiN coated cutting insert, mathematical model was developed for the effective surface finish criteria during machining of D2 steel and analysis was done in uncoded unit. Using multiple linear regression and correlation analysis, mathematical model for $\mathrm{Ra}$ is as follows:

$\mathrm{Ra}=0.2454-0.0014 \mathrm{v}+6.6444 \mathrm{f}+0.4722 \mathrm{t} \quad \mathrm{R}^{2}=0.98$

Table 5

ANOVA for regression model

\begin{tabular}{llllll}
\hline Source & DF & SS & MS & F & P \\
\hline Regression & 3 & 2.2088 & 0.7362 & 635.83 & 0.000 \\
Linear & 3 & 2.2088 & 0.7362 & 635.83 & 0.000 \\
Residual error & 23 & 0.0266 & 0.0011 & & \\
\hline Total & 26 & 2.2354 & & & \\
\hline
\end{tabular}

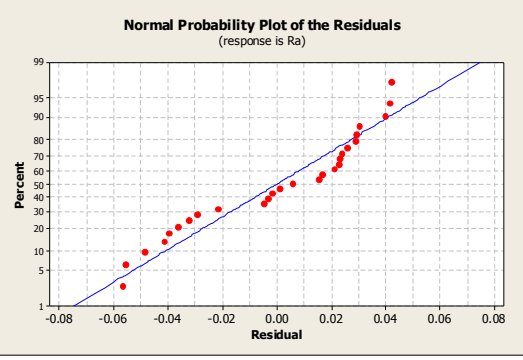

Fig. 8. Normal probability plot of the residuals

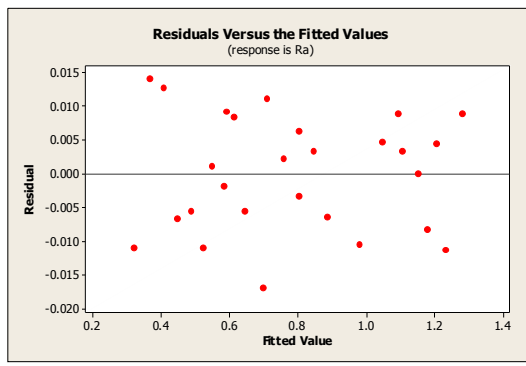

Fig. 9. Residuals vs. the fitted values

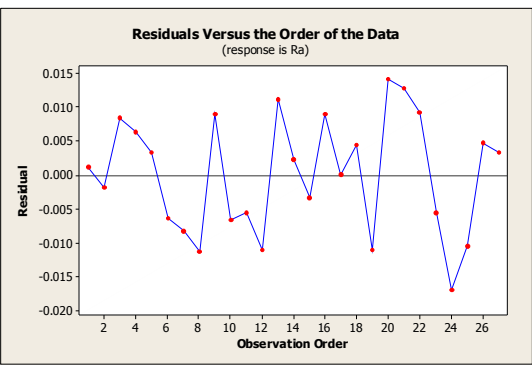

Fig. 10. Residuals vs. the order of the data

This analysis is carried out for a level of significance of $5 \%$, i.e., for a level of confidence of $95 \%$. $\mathrm{R}^{2}$ is called coefficient multiple determination and amount of reduction in the variability of surface roughness obtained by using the regressor variables (speed, feed and depth of cut). In regression model, the value of $\mathrm{R}^{2}$ being 0.98 indicates that $98 \%$ of the total variations are explained by the model. In this case, the $\mathrm{R}^{2}$ value is high, close to 1 , which is desirable. From ANOVA Table 5, analysing of variance shows that the terms having the values of probability less than 0.05 are significant. From Linear model, regression is significant. If the residuals plot approximately along a straight line, then the normality assumption is satisfied. A check on the normal probability plot vs. residuals of linear (Fig.8) shows that the residuals lie reasonably close to a straight line implying that errors are distributed normally and giving support that the terms mentioned in the model are significant. The graph of residuals vs. fitted values is shown in Fig. 9. No unusual structure is apparent. As its standardized residual is within the 
range of -3 to 3 , the model proposed is significant. The graph of residual vs. order of data (Fig. 10) shows the residual for the run order of experiment. This implies that the residuals are random in nature and don't exhibit any pattern with run order. Also fig of residual vs. order of data revealed that there is no noticeable pattern or unusual structure present in the data. This implies that the regression model proposed is adequate and there is no reason to suspect any violation of the independence or constant variation assumption.

\section{Conclusions}

The following conclusions can be drawn for effective machining to achieve better surface finish characteristics during hard turning.

1. In the case of machined surface roughness, the TiN coated tool produces lower surface roughness $\&$ within the recommended range of hard turning $(1.6 \mu \mathrm{m})$. This was believed to be due to high hardness, wear resistance, low coefficient of friction and high diffusion barrier properties of the TiN coated material.

2. The feed is the most influencing parameter for surface roughness. The higher feed rate led cutting tool to traverse the work piece too rapidly resulting in deteriorated surface quality.

3. The higher the cutting speed, the lower is the surface roughness observed. At higher cutting speeds, BUE formation disappears and chip-tool contact length decreases resulting in the improvement of surface finish of the work piece.

4. The experimental results show that average surface roughness are low at lower depth of cut but at a slower rate for which it can be considered as the less affecting parameter for surface roughness.

5. From the analysis of variance (ANOVA), it is observed that the feed is the most influencing parameter to surface roughness followed by cutting speed. Depth of cut is found to be insignificant in turning D2 steel.

6. For achieving good surface finish on the D2 work piece, higher cutting speed, lower feed and lower depth of cut are preferred. The optimal parametric combination for TiN coated cutting insert is v3-f1t1.

7. A multiple linear regression mathematical model for surface roughness was developed from the observed data. In regression model, the value of $\mathrm{R}^{2}$ being 0.98 indicates that $98 \%$ of the total variations are explained by the model. Thus, the developed model can be effectively used to predict the surface roughness on the machining of D2 steel with $95 \%$ confidence intervals.

\section{References}

Aggarwala, A., Singh, H., Kumar, P., \& Singh, M. (2008). Optimizing power consumption for CNC turned parts using response surface methodology and Taguchi's technique-A comparative analysis. Journal of Materials Processing Technology, 200, 373-384.

Basak, S., Dixit, U.S., \& Davim, J.P. (2007). Application of radial basis function neural networks in optimization of hard turning of AISI D2 cold-worked tool steel with a ceramic tool. Proc. IMechE, Part B: J. Engineering Manufacture, 221, 987-998.

Davim, J.P., \& Figueira, L. (2007). Machinability evaluation in hard turning of cold work tool steel (D2) with ceramic tools using statistical techniques. Materials \& Design, 28(4), 1186-1191. 
Gaitonde, V.N., Karnik, S.R., Figueira, L., \& Davim, J.P. (2009). Machinability investigations in hard turning of AISI D2 cold work tool steel with conventional and wiper ceramic inserts. International Journal of Refractory Metals \& Hard Materials, 27, 754-763.

Noordin, M.Y., Venkatesh, V.C., Chan, C.L., \& Abdulla, A. (2001). Performance evaluation of cemented carbide tools in turning AISI 1010 steel. Journal of Materials Processing Technology, $116,16-21$.

Ozel, T., Karpat, Y., Figueira, L., \& Davim, J.P. (2007). Modelling of surface finish and tool flank wear in turning of AISI D2 steel with ceramic wiper inserts. Journal of Materials Processing Technology, 189, 192-198.

Ozel, T., \& Karpat, Y. (2005). Predictive modeling of surface roughness and tool wear in hard turning using regression and neural networks. International Journal of Machine Tools \& Manufacture, 45, 467-479.

Paiva, A.P., Ferreira, J.R., \& Balestrassi, P.P. (2007). A multivariate hybrid approach applied to AISI 52100 hardened steel turning optimization. Journal of Materials Processing Technology, 189, 2635.

Quiza, R., \& Figueira, L., \& Davim, J.P. (2008). Comparing statistical models and artificial neural networks on predicting the tool wear in hard machining D2 AISI steel. International Journal of Advanced Manufacturing Technology, 37, 641-648.

Ross, P.J. (2005). Taguchi techniques for quality engineering. $2^{\text {nd }}$ edition, Tata Mc Graw hill pub.

Sahin, Y. (2009). Comparison of tool life between ceramic and cubic boron nitride (CBN) cutting tools when machining hardened steels. Journal of Materials Processing Technology, 209, 3478-3489.

Sahoo, A.K., \& Sahoo, B. (2012). Experimental investigations on machinability aspects in finish hard turning of AISI 4340 steel using uncoated and multilayer coated carbide inserts. Measurement, 45, 2153-2165.

Sahoo, A.K., \& Sahoo, B. (2011). Surface roughness model and parametric optimization in finish turning using coated carbide insert: Response surface methodology and Taguchi approach. International Journal of Industrial Engineering Computations, 2, 819-830.

Sahoo, A.K., \& Sahoo, B. (2013). Experimental investigation on flank wear and tool life, cost analysis and mathematical model in turning hardened steel using coated carbide inserts. International Journal of Industrial Engineering Computations, 4, 571-578.

Sahoo, A.K., Orra, K., \& Routra, B.C. (2013). Application of response surface methodology on investigating flank wear in machining hardened steel using PVD TiN coated mixed ceramic insert. International Journal of Industrial Engineering Computations, 4, 469-478.

Sahoo, A.K., \& Mohanty, T. (2013). Optimization of multiple performance characteristics in turning using Taguchi's quality loss function: An experimental investigation. International Journal of Industrial Engineering Computations, 4, 325-336.

Sahoo, A.K., Pradhan, S., \& Rout, A.K. (2013). Development and machinability assessment in turning $\mathrm{Al} / \mathrm{SiCp}$-metal matrix composite with multilayer coated carbide insert using Taguchi and statistical techniques. Archives of Civil and Mechanical Engineering, 13, 27-35.

Sahoo, A.K., \& Sahoo, B. (2013). Performance studies of multilayer hard surface coatings (TiN/TiCN $/ \mathrm{Al}_{2} \mathrm{O}_{3} / \mathrm{TiN}$ ) of indexable carbide inserts in hard machining: Part-I (An experimental approach). Measurement, 46, 2854-2867.

Sahoo, A.K., \& Sahoo, B. (2013). Performance studies of multilayer hard surface coatings (TiN/TiCN/ $\mathrm{Al}_{2} \mathrm{O}_{3} / \mathrm{TiN}$ ) of indexable carbide inserts in hard machining: Part-II (RSM, grey relational and techno economical approach). Measurement, 46, 2868-2884.

Singh, D., \& Rao, P.V. (2007). A surface roughness prediction model for hard turning process. International Journal of Advanced Manufacturing Technology, 32, 1115-1124.

Thamizhmanii, S., Bin Omar, B., Saparudin, S., \& Hasan, S. (2008). Surface roughness analyses on hard martensitic stainless steel by turning. Journal of Achievements in Materials and Manufacturing Engineering, 26 (2) 139-142. 
Vikram Kumar, CH.R., Kesavan Nair, P. \& Ramamoorthy, B. (2008). Performance of TiCN and TiAlN tools in machining hardened steel under dry, wet and minimum fluid application. International Journal of Machining and Machinability of Materials, 3 (1/2), 133-142. 